\title{
Engaging knowledge and the knower: Design considerations for emerging modes of academic staff development
}

\author{
Daniela Gachago ${ }^{1 \#}$, Barbara Jones ${ }^{2}$, Emmanuel Ekale Esambe ${ }^{2}$, Sonwabo Jongile ${ }^{2}$, and Eunice Ivala ${ }^{2}$ \\ ${ }^{1}$ University of Cape Town \\ ${ }^{2}$ Cape Peninsula University of Technology \\ ${ }^{\#}$ Corresponding Author: daniela.gachago@uct.ac.za
}

(Submitted: 5 October 2020; Accepted: 8 September 2021)

\begin{abstract}
Curriculum design is a complex undertaking that requires both epistemological and ontological work. While there is an increased need for academics to develop and strengthen their capacity to design curricula, particularly in the context of Universities of Technology, which have gone through an intense period of identity finding and re-curriculation, there is little support for academics involved in this kind of work. This paper reflects on four iterations of an academic staff development intervention aimed at supporting academics engaged in curriculum design and renewal, with a particular focus on designing flexible curricula. Using a learning design model along with eleven design considerations developed by Gachago, et al. (2020) for online academic staff development and Maton's Legitimation Code Theory - in particular the dimension Specialization - we show how curriculum work and learning design is iterative, contextual and messy. Most importantly, it is relational and involves collective sense-making. We recommend that each context needs to be carefully considered when designing courses, both face-to-face and online, and design considerations (such as motivation, facilitation, structuredness, level of collaboration) impact strongly on participants' engagement and consequently experiences.
\end{abstract}

Keywords: academic staff development, curriculum design, flexible learning, learning design, Legitimation Code Theory

\section{Introduction and Background}

Many structural, systemic, and institutional changes have emerged over the last few years, which make it essential for higher learning institutions to explore options of flexible learning. For instance, Goodyear (2015) reports widening access and burgeoning student enrolments, graduate underpreparedness for rapidly changing workplaces, and most importantly dwindling public funding as 
global challenges to Higher Education (HE). Furthermore, increasing competition by private higher education providers has forced public HE institutions to rethink their modes of provision of learning. Recently, the novel coronavirus commonly referred to as COVID-19 has led to the shutting down of cities and universities across the world, thus adding to the need for alternative ways of working, teaching, and learning (Quacquarelli, 2020).

South Africa's need for more flexible curriculum design can be linked to several factors: The changing student population, consisting more and more of 'non-traditional' students (NTS) who, as opposed to the 'traditional' conception of students can be older, engaged in some form of paid or unpaid work, and have a multitude of responsibilities outside of their studies. There are also growing needs and requirements for in-service/continuous professional development (CPD), necessitating flexible learning alternatives for people in the workplace that take into account their working and personal contexts and their learning needs (Jones and Walters, 2015). Additionally, HE institutions are looking for alternative income streams, as government subsidies decrease and technological advances make interactive distance education possible and efficient. These developments have necessitated policy changes, such as the 2014 Policy for the Provision of Distance Education in South African Universities (DHET, 2014), which allows contact institutions to offer distance education, i.e., education at a distance rather than on campus, and the draft Open Learning Policy Framework (DHET, 2017), which proposes open learning approaches and practices in the post-school sector.

South Africa also has particular issues to contend with, such as the widespread disruption of teaching and learning in HE by student-led protests, which has highlighted the inequality that persists in the country's tertiary system and pointed to the need for fresh approaches to addressing systemic problems in HE. In particular, the protests have drawn attention to the need to not only create epistemic access for diverse communities of students (Quinn and Vorster, 2019), but also the inclusion of student voices into the curriculum design process, and co-creating spaces where all students can flourish (Cook-Sather, et al., 2019; Ngoasheng, et al., 2019).

Curriculum development is a complex process that requires a myriad of different intersecting skills and knowledges, including disciplinary, pedagogical, policy and technological knowledge, among others. Universities of Technology (UoTs) in South Africa are undergoing an intense process of transformation, including re-curriculation of programmes and development of new qualifications in line with the new Higher Education Qualification Sub-Framework (HEQSF) (Engel-Hills, et al., 2019). The UoT, which is the centre of this case study, has been engaged in such curriculum activities for several years; by way of example, more than 70 new programmes needed to be developed before 2021 to ensure articulation and progression possibilities for students. To build the capacity for the development of the above programmes, the curriculum officers (COs Project) was introduced in the late 1990s. The aim of this programme was to capacitate curriculum officers (COs) in their respective academic departments, to support the development of new qualifications, and to offer targeted curriculum planning support. Key concepts emphasised in this project are the promotion of greater 
student inclusivity, including making the curriculum more meaningful, promoting active learning, and ensuring greater flexibility in the delivery of teaching and learning programmes. Offering courses in a blended learning format, with varying degrees of 'online' learning, is one way of providing more flexibility to students the COs were exposed to during the training.

Since 2017, staff from two academic staff development units, the Curriculum Development Unit and the Centre for Innovative Educational Technology, where the authors of this paper were based during the facilitation of these courses, have been working with academic departments that are designing advanced diplomas, postgraduate diplomas and Honours degrees, which need to accommodate working students by offering flexible learning options using blended learning. At this UoT, blended learning is defined as a 'thoughtful combination of different pedagogical approaches, drawing on a range of teaching and learning theories, using a variety of tools and technologies, to create context-sensitive and flexible learning experiences with and for our learners' (Gachago, et al., forthcoming).

Support to the COs and departments in developing the new HEQSF qualifications has taken various forms, such as seminars, workshops and CO forums that have focused on interrogating and discussing the principles, theories, and practices of programme and curriculum development in a UoT context. However, a more intensive and systematic approach to programme and curriculum development was needed to assist these academics to conceptualise and design educationally robust learning programmes that, at the same time, conform to the prescriptive requirements and templates of the national accreditation and registration authorities. Moreover, to build longer-term curriculum development capacity in the institution, these interventions needed to promote the social construction of knowledge through collaborative activities among participants and with their colleagues in academic departments.

We decided, therefore, to pilot a blended learning short course in the first semester of 2019, offered as a series of nine workshops with online facilitator-supported activities in between the faceto-face sessions. This had some successes but also some challenges, such as staff being from different campuses. Also, staff has high teaching loads which made it difficult to attend the course face-to-face and long-term unsustainable demands on the facilitators. Therefore, in the second semester, to mitigate some of these challenges, and to open the course to a wider spectrum of academics interested in curriculum development, we redesigned the short course as a largely online offering, supported by occasional workshops for specific curriculum design activities. This paper reflects on a design journey comprising four iterations of a curriculum development course, from a face-to-face provision of learning to a blended learning format and finally two iterations of an online course. Using an action research approach, we integrated Kolb's experiential learning cycle with elements of Specialization in Legitimation Code Theory (LCT), focusing on the entanglement of knowledge and knowers, to understand how different modalities of delivery could support academic staff in designing flexible and context-sensitive curricula. 
In this paper, we explore the challenges faced, and possibilities emerging, from exploring emergent modes of academic staff development, which have become increasingly relevant in these times of remote teaching and learning, even more so in times of COVID-19.

\section{Emerging modes of academic staff development}

The need to develop new academic programmes is an opportunity for much-needed curriculum transformation, but also demands a rethink of the UoT's current academic staff development approaches. Research into academic staff development for integrating technology into teaching and learning seems to agree that, in general, these programmes follow a 'one-size-fits-all' workshop approach with little in the way of flexible or blended delivery options, making it difficult for lecturers to participate equitably. Also, these interventions tend to focus on technology rather than pedagogy (Lane, 2013; Bali and Caines, 2018).

We suggest that one of the most important aspects of academic staff development may be the unlearning of established habits and beliefs around teaching and learning. Baran, et al. (2011) suggest that there should be a focus on professional development that promotes critical reflection, supports the integration of technology and pedagogical inquiry and empowers blended/online teaching and learning. Also, attention needs to be placed on the structure of a blended course with emphasis on a design that enables participants to progress in the course in a scaffolded approach such as the 5 Stage model of online learning proposed by Gilly Salmon (2004). When facilitating courses on blended learning, one should tailor them to provide authentic, evidence-based (drawing from theory and practice) and chunked courses that allow for flexible participation, focusing on effective situated delivery; supporting communities of practice and integration into the institutional academic community (see for example Ní Shé, et al., 2019). These design considerations support course participants, who not only have to deal with new knowledge but might also struggle with these new ways of learning.

There is a small but growing body of knowledge that explores these more flexible, open, equitable (Bali and Caines, 2018), 'untethered' (Leafstedt and Pacancsky-Brock, 2016) or 'networked' (Gachago, et al., 2020; NLEC, et al,, 2021) approaches to academic staff development. Leafstedt and Pacancsky-Brock (2016: n.p.) defined untethered academic staff development as 'learner-centred, grounded in the use of online networks to share practices, and [which do] not require faculty to be on campus to learn. Untethered places value on sharing and the relational ties between faculty, as opposed to the number of people in a room at a particular time'. Similarly, Gachago, et al. (2020) positioning the philosophical roots of networked learning in the work of Dewey and Freire, emphasised relationships and collaboration rather than technology and openness in attitude, learner collaboration, self-directed learning, and authentic learning. 


\section{Specialization in Legitimation Code Theory (LCT)}

Academic staff development traditionally focuses on constructs that build the 'knower'. That is training in values, beliefs and practices that enable one to thrive as an academic in the higher education space. However, traditionally lecturers are recruited because of their disciplinary knowledge and not necessarily on their ability to design or create meaningful learning experiences for their students. This presents a contradiction that is common in many higher education settings. LCT provides tools that one can use to engage with this contradiction, such as Specialization (Maton, 2016b), to make attempts towards bridging the 'knowledge-knower gap'.

Legitimation Code Theory has been described as a conceptual and analytical 'toolkit'; a 'practical theory' containing theoretical tools that can be used to bridge the divide between theory and practice in education and other disciplines (Maton, 2014: 15). There are five dimensions in LCT, namely: Specialization, Semantics, Autonomy, Temporality and Density (Maton, 2016b). Each of these dimensions engages with different aspects of practices, exposing the underlying organising principles of such practices. These organising principles of practices shape what Bourdieu (1991, in Maton, 2014: 7) terms the 'space of possibles' - the 'range of stances actors see as viable and legitimate' (Maton, 2014: 7). While LCT offers five dimensions, this paper adopts one - Specialization

- to explore the challenges and opportunities which lecturers experienced in academic staff development across different modalities.

Specialization focuses primarily on the nature of a field: that is, 'what makes this field, and those within it who count themselves as belonging to it 'special'?' (Clarence and McKenna, 2017:41). Specialization explores how the organising principles of a field make the field, and those who act in the field, legitimate in the field (Maton, 2014). Building from this, Specialization proposes two sets of relations that compete for legitimacy in terms of what counts as achievement in a field: epistemic relations (ER), which refer to how the field relates to the knowledge contained within it (relations with the object), and social relations (SR), which refer to how the actors (also known as subject/knower) relate to the field (Maton, 2014). Epistemic relations (ER) and social relations (SR), in other words, refer to relations to knowledge and knowers respectively. Chen and Maton (2011: 131) explain this as follows: 'Underpinning LCT (Specialization) is the notion that educational practices and contexts represent messages as to both what is valid to know and how, and also who is an ideal actor (learner or teacher).'

Maton (2014) argues that every field or practice presents relations to both the object (the knowledge) and the subject (the knowers) - at varying degrees of relative strength. Some fields foreground the knowledge as more prominent (i.e. Engineering), while others favour the knowers as a basis for achievement (i.e. the Humanities). The preferences for either foregrounding the knower or the knowledge are reflected in how a curriculum is designed and in the disciplinary teaching and learning practices. 
To further explain the relations between the epistemic relations and the social relations, Maton (2016a: 13) uses a continuum of positive and negative axes, resulting in four Specialization codes, namely:

- knowledge codes (ER+, SR-): where possession of specialized knowledge, principles or procedures concerning specific objects of study is emphasised as the basis of achievement, and the attributes of actors are downplayed;

- knower codes (ER-, SR+): where specialised knowledge and objects are downplayed and the attributes of actors are emphasized as measures of achievement, whether viewed as born (e.g. 'natural talent'), cultivated (e.g. 'taste') or social (e.g. feminist standpoint theory);

- elite codes $(\mathrm{ER}+, \mathrm{SR}+)$ : where legitimacy is based on both possessing both specialist knowledge and being the right kind of knower; and

- relativist codes (ER-, SR-): where legitimacy is determined by neither specialist knowledge nor knower attributes - 'anything goes'.

To put this in context, a field of study where the focus is predominantly on developing knowledge, procedures, principles, and/or formulae in the field, would be denoted as having stronger epistemic relations (ER+) and weaker social relations (SR-). Conversely, a field where the focus is predominantly on key dispositions, aptitudes, experiences, abilities, or identity would be referred to as having stronger social relations $(\mathrm{SR}+)$ and weaker epistemic relations (ER-). Therefore, in Specialization, we would commonly refer to a knowledge code as ER+, SR-; and to knower code as SR+, ER- (Maton, 2014).

Maton (2007: 97) uses a Specialization plane to enact the four Specialization codes to bring to the fore the organising principles which underpin a field both in thinking and in context, as seen in Figure 1 below.

\section{Situating academic staff development within LCT}

Higher education is at a crossroads and facing serious existential introspection (Winter, et al., 2017; Barnett, 2009; Barnett, 2006). Barnett's (2012: 253) call for supporting learning for an uncertain future is even more cogent in these times of uncertainty as a result of COVID-19. He sees the educational project as an epistemological but even more so an ontological one:

Under these conditions of uncertainty, the educational task is, in principle, not an epistemological task; it is not one of knowledge or even knowing per se. It is not even one of action, of right and effective interventions in the world. For what is to count as a right or an effective intervention in the world? Amid super complexity, the educational task is primarily an ontological task. (Barnett, 2012: 252) 


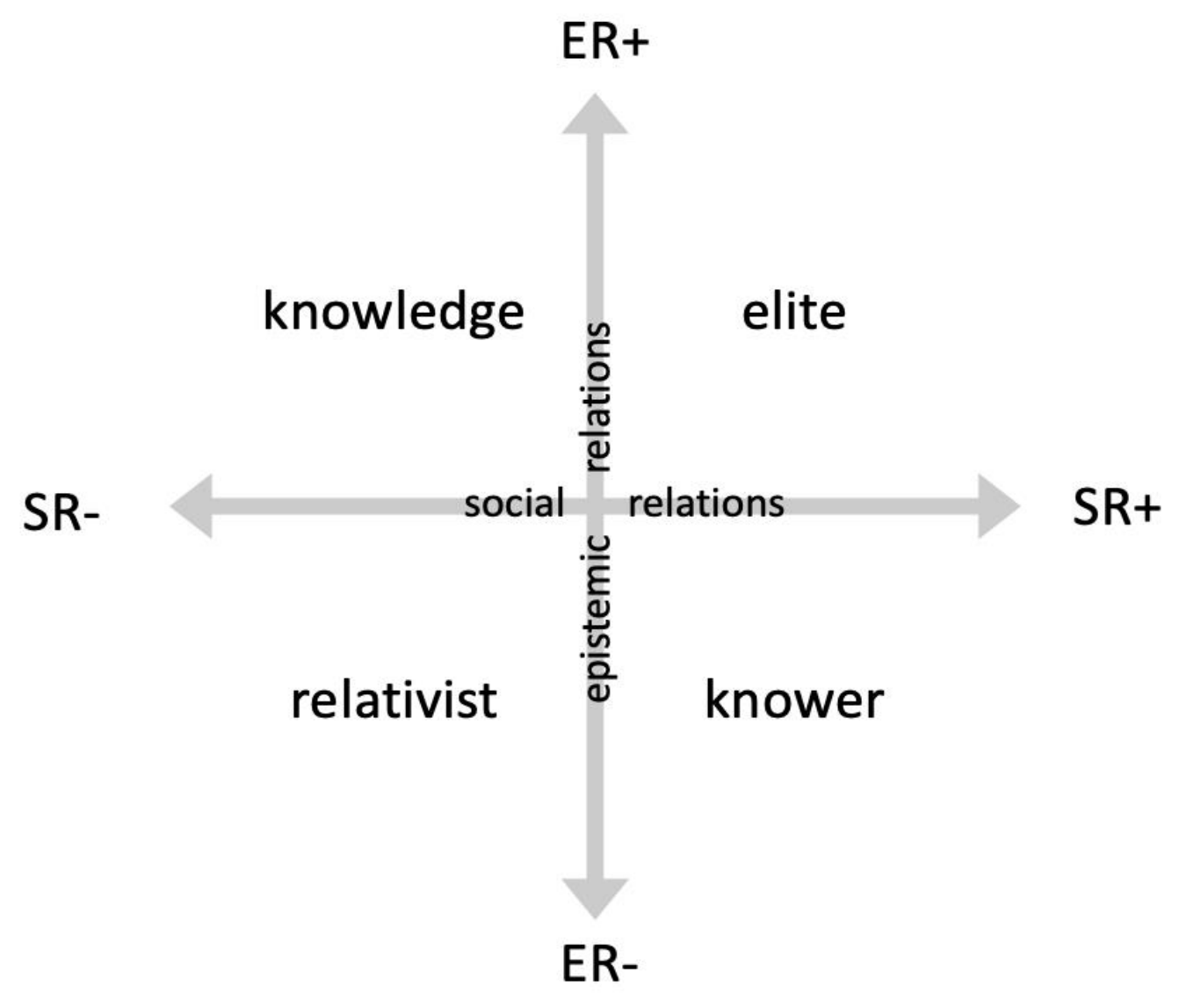

Figure 1: A Specialization plane showing epistemic and social relations (Maton, 2014:30)

In this paper, we follow the suggestion of Dall'Alba and Barnacle (2007), that knowledge and the knower are intricately dependent on each other. This dependency is both temporal and contextual and means that teaching and learning need to create an understanding of how history shapes subjectivities and practices and how subjectivities and positionalities shape access to knowledge (Thomson, 2001: 248).

Academic staff development has tended to be concerned with the knower, focusing on issues of identity and positionality of lecturers and students and how these impact teaching and learning (Vorster and Quinn, 2017). Working across many disciplines, knowledge is not necessarily foregrounded, but academic staff developers encourage academics to reflect on their knowledge and knower practices in their disciplines. However, when it comes to curriculum design, both knowledge and knower relations are essential. Specialist curriculum knowledge areas include an understanding of learning theories, national and institutional educational policies, student and employment contexts, professional body requirements, pedagogical knowledge, among others, and how these all intersect with distinctive disciplinary knowledge in designing a learning programme and curriculum. Academic staff developers, in turn, need to be able to translate the 'technical' aspects 
of curriculum design for academics and encourage academics to critically engage with and challenge their assumptions of teaching, learning and knowledge/knower relations in a rapidly transforming higher education context (Quinn and Vorster, 2019).

\section{Methodology}

The study comprises four design iterations of a curriculum development short course that was offered in 2019 to academic staff involved in developing new qualifications, particularly postgraduate diplomas, bachelor, and honours degrees. Our research question is: How do certain design decisions influence participants' experiences of academic staff development interventions with a particular focus on knowledge and knower relations? Or, what happens when we move academic staff development online?

With its emphasis on intervention and change, action research is a suitable approach for investigating flexible models to teaching and learning as well as infusing blended learning into programme design and delivery (Heinze and Procter, 2004). Action research is critical and collaborative and therefore aligns well with our considerations of flexibility, appropriateness and multimodality in programme design and programme delivery. It also aligns well with social constructivist theories of learning (Vygotsky, 1978; Dewey, 1938) which underpinned the pedagogical decisions taken in designing the four iterations. At its core, the process of action research, based on Kolb's experiential learning cycle (1984), revolves around a phased strategy of plan, act, observe, reflect and re-plan (see Figure 2), which is appropriate for a small-scale qualitative and participatory study such as the one reported in this paper.

Data collection methods included the following:

- Observations of workshops, group discussions and content analyses of the four iterations, as well as of the learning activities produced by participants.

- Qualitative feedback, which was obtained from participants at the end of each workshop/learning session.

- Surveys and semi-structured interviews with participants (academic staff members) on the courses. 
Concreate experience

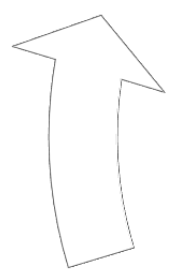

Active experimentation

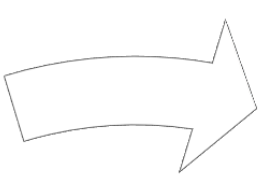

\section{Reflective} observation

Figure 2: Kolb's experiential learning cycle

To make sense of the data, we engaged in a four-step process: (i) establishing design considerations and identifying theories that inform a blended academic staff development course; (ii) capturing the design iterations; (iii) interpreting the data using identified theories; and (iv) a reflection on each of the iterations at the end of each of the action research cycles based on the data collected and its interpretation at those points in time (see Table 1).

To understand how different learning designs affect learning experiences, we adopted the 11 design considerations for online academic staff development developed by Gachago, Pallitt and Bali (2020). Table 1 below captures these dimensions and brief descriptions of each. 
Table 1: Design dimensions and descriptions (adapted from Gachago, et al., 2020: 6-7)

\begin{tabular}{|c|c|}
\hline Design dimension & Description/explanation \\
\hline Degree of Facilitation & $\begin{array}{l}\text { To what extent are the facilitators working directly with participants? How do the } \\
\text { participants experience the facilitators? How do the participants/facilitators see } \\
\text { the course as building on their facilitation skills? }\end{array}$ \\
\hline Degree of Openness & $\begin{array}{l}\text { Is access to the course open to people outside of the institution or restricted to } \\
\text { within the institution? How do the participants experience this access? What is the } \\
\text { relationship of this access to knowledge? }\end{array}$ \\
\hline Degree of Structure & $\begin{array}{l}\text { To what extent was there a course structure that was planned and followed? How } \\
\text { do participants experience the planning of the course? Do participants see the } \\
\text { course as highly structured, semi-structured or very flexible? How does the } \\
\text { structure affect the participants' appreciation of the course? }\end{array}$ \\
\hline $\begin{array}{l}\text { Degree of } \\
\text { Voluntarism }\end{array}$ & $\begin{array}{l}\text { To what extent was lecturers' participation voluntary versus mandatory? Is } \\
\text { enrollment for the course compulsory or optional? How does this affect the way } \\
\text { the participants experience the course? }\end{array}$ \\
\hline Degree of Linearity & $\begin{array}{l}\text { To what extent does the course flow in a particular order? How does the course } \\
\text { progress from beginning to end? Is there a clear order? How do the participants } \\
\text { experience this? }\end{array}$ \\
\hline $\begin{array}{l}\text { Degree of } \\
\text { Certification }\end{array}$ & $\begin{array}{l}\text { Is a certificate of completion offered for completing the course? Is the certificate } \\
\text { recognised beyond the institution? }\end{array}$ \\
\hline Degree of Eventiness & $\begin{array}{l}\text { How is new material presented during the course? Is it planned and released on } \\
\text { schedule, or all at once? Are there scheduled synchronous meetings (face to face } \\
\text { and online)? What are the participants' experiences of synchronous meetings? }\end{array}$ \\
\hline Content or Process & $\begin{array}{l}\text { Does the course present a clear curriculum (content) with learning outcomes, or } \\
\text { does it have loosely stated goals to achieve (process)? How do the participants } \\
\text { experience this? }\end{array}$ \\
\hline $\begin{array}{l}\text { Degree of } \\
\text { Homogeneous / } \\
\text { Personalised Learning }\end{array}$ & $\begin{array}{l}\text { Are participants expected to follow a set content/learning path of study, or can } \\
\text { the content/learning path be chosen/adapted based on participants' disciplines, } \\
\text { expectations, interests? }\end{array}$ \\
\hline Degree of Playfulness & $\begin{array}{l}\text { To what extent does the course employ games or other "fun" activities to keep } \\
\text { the participants engaged? How do the participants experience this? }\end{array}$ \\
\hline $\begin{array}{l}\text { Degree of } \\
\text { Collaboration }\end{array}$ & $\begin{array}{l}\text { Do participants study only on their own, or are they encouraged to collaborate } \\
\text { with peers and facilitators? To what extent is a collaboration facilitated or } \\
\text { encouraged into the course design? How do they experience this? }\end{array}$ \\
\hline
\end{tabular}

These dimensions then led us to the design, in Table 2, of a translation device which enables us to highlight Specialization codes and how they can manifest in the study. 
Table 2: Epistemic relations and social relations: A translation device

\begin{tabular}{|l|l|}
\hline Concept & Example \\
\hline ER+ & Dense course curriculum, strong focus on knowledge transfer. \\
\hline ER- & $\begin{array}{l}\text { Less focus on content and stronger focus on process, such as identity work, } \\
\text { personal growth of participants. }\end{array}$ \\
\hline SR+ & $\begin{array}{l}\text { Strong emphasis on building a learning community through facilitation, } \\
\text { collaboration, and peer support. }\end{array}$ \\
\hline SR- & Self-study, independent learning design. \\
\hline
\end{tabular}

\section{Findings}

\section{Reflection on design iterations}

Having outlined the 11 dimensions (in Table 1), we reflect on participants' and facilitators' experiences of these four design iterations (see figure 3) in the section below. Of interest to us is how the design dimensions one needs to consider when moving academic staff development online, to provide more flexibility and authenticity, impact on participants' experiences. This is particularly important vis-a-vis epistemic relations and/or social relations - that is, a relation more to the knowledge or more to the knower as summarised in the translation device. In other words, what we sought to explore in this paper is the extent to which what we aimed for in the design of the course was achieved - based on participants' and our reflections.

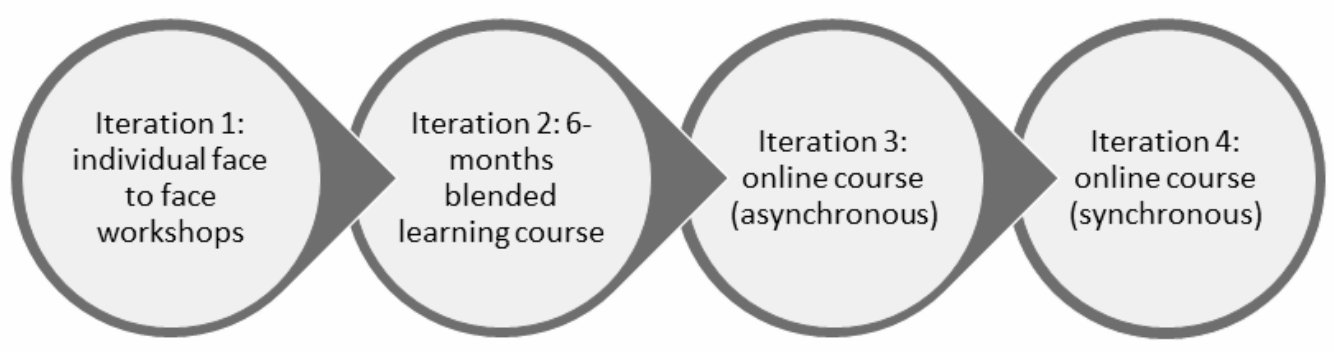

Figure 3: Four design iterations

Design iteration 1: Individual on-demand workshops on 'Programme/Curriculum Design' (collaborative, face-to-face, and synchronous)

During 2018, we designed two workshops for departments engaged with curriculum design: one for designing complete academic programmes, the other for designing curricula for individual subjects in a programme. Both were hands-on workshops, where departmental design teams were encouraged to envision their courses and to start thinking about how to offer a more flexible provision of their courses. These were offered on request to faculties and academic departments. 
While the workshops were well received and provided a space for creative engagement in often diverse teams, one consistent feedback was that design teams struggled to transfer the interactive, creative work from the workshop into a written proposal format for the prescriptive templates for new HEQSF qualifications. Our analysis of this situation reveals that the participants voluntarily attended the workshops, and that the structure of the workshops was not strongly bound and allowed for collaboration and fun-filled group tasks. This was considered to be focusing on stronger social relations (ER-, SR+). But, when participants engaged individually on completing the templates for their respective HEQSF qualifications, they found it challenging applying the knowledge from the workshop to their templates. This led us to decide to offer a more structured, longer-term facilitated process, which is described in design iteration 2.

Design iteration 2: Blended learning course 'Designing HEQSF-aligned programmes' (collaborative, face-to-face workshops supported by asynchronous online resources \& activities)

The course was structured around decisions that need to be made when designing a new qualification and was scaffolded to facilitate the completion of the required templates of the national authorities and professional bodies.

We offered the first iteration of this course over six months with nine, half-day, face-to-face workshops every three weeks; supported by resources on the institutional learning management system (LMS), Blackboard. Also, workshop learning material, recorded presentations and activities were uploaded onto the LMS after the workshops for participants to access and engage with.

The workshops were organised around hands-on, topic-related activities in the classroom and participants were encouraged to form design teams with participating colleagues from the same academic department or faculty. Explicit links were made to topics covered in preceding workshops and to design activities, to scaffold learning and to maintain coherence. Design of individual workshops happened 'on the fly', workshop by workshop, responding to participants' feedback, modelling a 'design-on-the-go' approach to curriculum and course development (Taheri, et al., 2016), and following our action-learning research processes.

The course demanded a serious engagement with the knowledge needed to conceptualise an HEQSF-aligned qualification. It included theoretical perspectives on teaching and learning and challenged participants to interrogate their positionality as educators. It also explored internal (institutional, faculty, departmental) and external (world of work, comparative positioning of the qualification to cognate national/international qualifications) contextual factors and national and institutional education policies that shape the conceptualisation of a qualification. These are attributes which made the first half of the course to have stronger epistemic relations and weaker social relations $(\mathrm{ER}+, \mathrm{SR}-)$, that is, a knowledge code.

The course also included more creative activities as part of hands-on programme and curriculum design workshops, cohering around pedagogical and blended and flexible delivery 
considerations, especially concerning learners' contexts and the characteristics and purpose of the qualification. Although collaboration was central to all activities, playfulness characterised the activities in the second half of the course; activities such as creating learner profiles, knowledge trees, and the use of storyboarding to map teaching, learning and assessment activities of individual subjects. It thus foregrounded stronger social relations. When considering the whole course using Specialization, this iteration focused on both a knowledge code $(\mathrm{ER}+, \mathrm{SR}-)$ and a knower code (ER, SR+).

Each workshop topic was linked to an online design activity in Google Docs, aimed at the completion of the prescribed templates for accreditation of new qualifications, and which allowed for written peer-to-peer and facilitator feedback.

Participation in the workshops was lively and relatively consistent and out of the 34 academics who enrolled, 26 completed the workshop programme and several design teams completed all the online design activities. In their evaluative feedback, participants commented positively on the interactive and collaborative nature of the programme, the opportunity to engage with colleagues from different departments and faculties and the relevance of the material to their practice. They also spoke about the importance of action and reflection, and especially of having time in the workshops for reflection on their practice. It was encouraging that participants were keen to take what they had learned back to their academic departments to share with their colleagues.

However, as pointed out repeatedly by participants, time was the biggest challenge they faced, to both attend the workshops and to work on the online design activities. They however also noted that it was easier to schedule a time to attend the workshops than to catch up on their own. Therefore, this uninterrupted time to focus on what they needed to do, was a strong motivation for them to attend the workshops. Moreover, a final workshop, specifically aimed at how to fill in the prescribed templates, turned out to be critically important. As noted by the participants, it was only through the collaboration, negotiations, and discussions with colleagues, intensively supported by facilitators, that the messy curriculum design work could be translated into the specialist curriculum language required by the technical templates.

Finally, although both participants and the facilitation team testified that this had been a great learning experience, face-to-face workshops had limitations. As well as time issues, we were a small facilitation team and not able to scale this kind of intervention across the multi-campus institution and to the approximately 1000 academics that we support.

Overview of design iterations 3 \& 4: Moving academic staff development online

Partly because of capacity constraints we decided to offer the subsequent iterations of the course in an online learning format. This format was intended to offer greater flexibility for lecturers, constrained by their geographical location and teaching schedules, to participate, and for more authentic modelling of flexible/blended learning course design. It was also aimed at a wider audience 
than purely at those involved in the new programme design and allowed participants to select only those topics that they were interested in.

This online learning course ran over three months, with new topics released every two weeks, following the thematic structure of design iteration 2. Also, along the lines of design iteration 2, this course was divided into two modules, which in this paper we will call design iterations 3 and 4 , and for which we continued to follow an action research approach. Compared to design iteration 2, where the main facilitation and engagement happened face to face, supported by online activities, design iterations 3 and 4 relied predominantly on online engagement, supported by face-to-face workshops. Iterations 3 and 4 will be discussed below in detail.

Design iteration 3: Online module 1 'Theory of curriculum design and external/internal stakeholder context' (independent study, mainly asynchronous and self-study)

The online module ran over two months and was offered through the institutional Learning Management system (LMS). The online learning was supported by two half-day, face-to-face workshops to facilitate particular collaborative activities. Additional online self-study design activities were offered to enable participants to complete the prescribed accreditation templates documentation as they progressed. Although these activities were not facilitated, online feedback was given by the facilitators. Thus, even though there were two face-to-face sessions, this module was mainly asynchronous.

Weekly learning activities for this design iteration, which focused on the conceptualisation of a qualification (stronger epistemic relations and weaker social relations $(\mathrm{ER}+, \mathrm{SR}-)$, thus a knowledge code), as in the first half of design iteration 2, were structured in the following way: a screencast with an overview of the topic, some readings, a topic for the discussion forum and a reflective blog task for participants. In total, participants were expected to spend 2-3 hours per week on online learning activities. The content and structure were decided beforehand, although facilitators created some content as the course progressed. Participants self-assessed their progress by ticking topics off as they completed them.

Although 28 participants signed up, there was low participation in the asynchronous online activities; the LMS analytics showed that very few even accessed the material available, and by the time the course closed, no one had attempted any of the activity sheets. Similarly, there was no engagement in the discussion forums, despite frequent communications from the course facilitators to motivate and remind participants. Even the two workshops were very poorly attended.

On reflection, the interactive workshop model of design iteration 2 was difficult to replicate online. Scheduled workshops allowed participants, even those with limited time resources, to carve out time to engage in conversations and learning that is difficult to achieve in an online context. Challenges inherent in certain online learning designs, which are predominantly based on self-study, in participants' own time and at their own pace while meeting their daily work demands, are 
exacerbated if there is no incentive to participate beyond personal interest. Face-to-face engagements provide a forced break from normal day-to-day work and, as participants commented, 'time to interact with colleagues from different departments and faculties, can enrich meaningmaking and enhance their understanding of difficult topics.' Furthermore, the knowledge content, pace and scope of the course may have been intimidating, especially for participants learning by themselves, compared to the collaboration and collegiality of engaging with the material in the faceto-face workshops. Most importantly, the lack of engagement with participants did not allow us to respond to their feedback and needs or adjust course design 'on the go', as we did in previous iterations. Using Specialization, we code this situation to exhibit stronger epistemic relations and weaker social relations (ER+, SR-) for two reasons: i) the course required intensive engagement with knowledge issues - knowledge of curriculum theory and design - which are dense and technicist $(E R+)$ and ii) the self-study, asynchronous nature of the module design isolated the participants from the face to face interactive space which they have been accustomed to and thus requiring strong personal motivation, beliefs, and personal readiness possibly accounting for poor participation in the module (SR-).

Design iteration 4: Online course 'Flexible and blended learning design' (collaboration, synchronous)

In response to the challenges of low participation in design iteration 3, this iteration was designed to allow more interaction and engagement with topics online. The module focused on flexible and blended programme and curriculum design, as in the second half of design iteration 2 , which lends itself to being experiential and process-oriented (hence, weaker epistemic relations and stronger social relations, ER-, SR+), thus a knower code. Although it was not as content-heavy as design iteration 3, a good grasp of learning theories was necessary to inform their curriculum design decisions, and these were introduced in the first session. This introduction in the first session was an opportunity for key concepts to be covered, thus allowing the participants to be eased into the module.

The module was offered on Google Sites, to widen access and provide opportunities for more creative design modalities than the institutional LMS would allow. To promote active learning, synchronous engagement was offered through weekly webinars, which allowed participants to follow a structured learning routine and engage in social learning in line with more flexible, open, equitable (Bali and Caines, 2018), 'networked' (Gachago, et al., 2020) approaches to academic staff development described above. The online learning was reduced to one or two short activities which were oriented towards collaboration with other participants, such as collective annotation of readings and videos, to re-insert the atmosphere of creativity and playfulness that tend to characterise our face-to-face staff development activities. 
Although only seven academics enrolled for this module, participation in the weekly webinars was good. In their feedback, participants responded positively to the webinars (which for many participants was still a novel experience at that time), and the online learning activities (both individual and collective), helped them find structure and rhythm to their learning experience. They commented that the intimacy of the webinars allowed for ongoing conversations, contributing towards the building of a learning community across the institution, and provided opportunities to listen to the recordings in their own time. They also mentioned the short and easily accessible, critical readings that sparked provocative conversations, and the value of the final two-day design workshop, which consolidated the contents of the module and allowed for productive engagement and discussions among participants.

\section{Design considerations and Specialization}

Our broad research objective for this project was to explore emerging academic staff development interventions, i.e., moving academic staff development online. The four design iterations discussed above have shown how the course was iteratively developed following an action research process, of planning, implementation, observation, reflection, and re-planning/improvement. The course iteration reflections demonstrate why certain decisions were made at each stage of the iteration, the design considerations that informed them, and how those decisions impacted the participants' experiences.

Specialization helped us analyse the organising principles that formed the basis for claims to legitimacy across the different design iterations. Our overarching aim for these academic staff development initiatives was twofold: generally, academic staff developers are mostly concerned with engaging the knower, encouraging academics to reflect on who they are, who their students are and how this impacts their teaching and learning practices. However, for this particular course, we also needed to focus on the field of curriculum development - a highly specialised knowledge area - as well as the technicalities of completing the prescribed templates for new qualification accreditation and registration.

The four design iterations were designed to address different learning outcomes: iteration 1, was focused on the knower; iteration 2, focused on knower and knowledge, iteration 3, hinged on knowledge, and iteration 4 again focused more on the knower. From an analysis of the facilitators' reflections, we can see that our aims for these iterations did not always correspond with participants' experiences, as shown in Table 3 below.

Maton's notion of Specialization (2014) allowed us to understand the participants' experiences in terms of epistemic relations and social relations; and opportunities and challenges that emerged when moving academic staff development online. Table 3 below captures selected design principles in each iteration of the courses, aligns them to relevant Specialization codes, and shows how Specialization helped us to better understand participants' experiences. 
Table 3: Design considerations per iteration and alignment to Specialization, our aims for the iterations and participants' experiences

\begin{tabular}{|c|c|c|}
\hline Iteration & Design considerations & $\begin{array}{l}\text { Alignment to Specialization and how the } \\
\text { design impacted on participants' } \\
\text { experiences ) }\end{array}$ \\
\hline 1 & $\begin{array}{l}\text { Closed (institution only) } \\
\text { Highly facilitated } \\
\text { Loosely structured } \\
\text { Linear } \\
\text { Non-certified } \\
\text { 'Eventy'- date-bound } \\
\text { Low degree of homogeneity (workshops } \\
\text { can be adapted to target group) } \\
\text { Process-oriented } \\
\text { Playful } \\
\text { Strong collaborative element }\end{array}$ & $\begin{array}{l}\text { Participants experienced attributes of } \\
\text { problem-solving, risk-taking, personal } \\
\text { agency, collaboration/discussions and } \\
\text { creativity. The actual HEQSF proposals } \\
\text { (curriculum) and what it takes to get it right } \\
\text { (procedures/content) was not covered. } \\
\text { Therefore, the focus was on the knower and } \\
\text { not the knowledge at this stage: } \\
\text { Aim: ER-, SR+ } \\
\text { Experience: ER-, SR+, }\end{array}$ \\
\hline 2 & $\begin{array}{l}\text { Closed (CPUT only) } \\
\text { Highly facilitated } \\
\text { Highly structured } \\
\text { Linear } \\
\text { Non-certified } \\
\text { 'Eventy'- date-bound } \\
\text { High degree of homogeneity } \\
\text { Process and content-oriented } \\
\text { Playful } \\
\text { Strong collaborative element }\end{array}$ & $\begin{array}{l}\text { The focus here was on the content } \\
\text { (knowledge) and the procedures it takes to } \\
\text { develop a new curriculum. However, there } \\
\text { was also an emphasis on } \\
\text { discussion/collaboration/sharing of } \\
\text { experiences and lecturer } \\
\text { identity/positionality. Facilitated through a } \\
\text { blended approach, participants' feedback } \\
\text { covers both content, and the experiences of } \\
\text { engagement and activities during face to } \\
\text { face workshops: } \\
\text { Aim: ER+, SR+ } \\
\text { Experience: ER+, SR+ }\end{array}$ \\
\hline 3 & $\begin{array}{l}\text { Closed (institutional LMS) } \\
\text { Low facilitation } \\
\text { Highly structured } \\
\text { Linear } \\
\text { Non-certified } \\
\text { Not date-bound } \\
\text { High degree of homogeneity } \\
\text { Content oriented } \\
\text { Serious } \\
\text { No collaborative element }\end{array}$ & $\begin{array}{l}\text { The focus here was on getting the } \\
\text { participants to master how to complete } \\
\text { their course proposal templates for HEQSF. } \\
\text { The drills, procedures, and knowledge this } \\
\text { entailed were covered. Participation was } \\
\text { voluntary. } \\
\text { Transferring the knowledge gained through } \\
\text { the online content to individual projects was } \\
\text { minimal; and it seemed participants } \\
\text { struggled to find the motivation to } \\
\text { complete the work on their own volition: } \\
\text { Aim: ER+, SR-- } \\
\text { Experience: ER-, SR- }\end{array}$ \\
\hline
\end{tabular}


Table 3: Continued

\begin{tabular}{|c|c|c|}
\hline Iteration & Design considerations & $\begin{array}{l}\text { Alignment to Specialization and how the } \\
\text { design impacted on participants' } \\
\text { experiences ) }\end{array}$ \\
\hline 4 & $\begin{array}{l}\text { Open (open platform Google Sites) } \\
\text { Strong facilitation } \\
\text { Highly structured } \\
\text { Linear } \\
\text { Non-certified } \\
\text { Date-bound } \\
\text { High degree of homogeneity } \\
\text { Process oriented } \\
\text { Playful } \\
\text { Collaboration }\end{array}$ & $\begin{array}{l}\text { The act of reflection relates to a knower } \\
\text { code as it is an innate disposition. } \\
\text { Focus on collaboration and dialogue, } \\
\text { encouraged through the weekly webinars } \\
\text { and collaborative online activities. } \\
\text { Participants embraced the knower code: } \\
\text { Aim: ER-, SR+ } \\
\text { Experience: ER-, SR+ }\end{array}$ \\
\hline
\end{tabular}

From the analysis in Table 3 above, we can map participants' experiences in a Specialization plane as follows:

$\mathrm{ER}+$

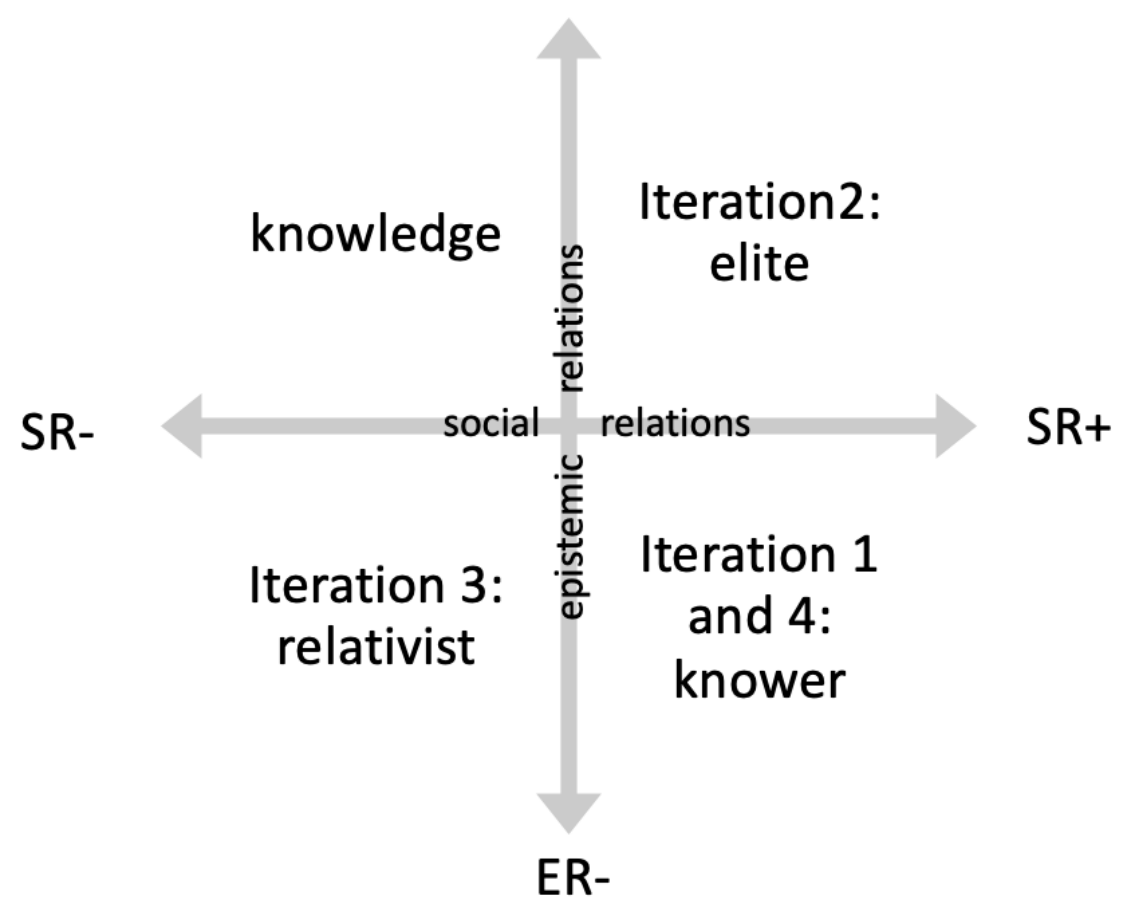

Figure 4: Mapping of participants' experiences on a Specialization plane (adapted from Maton, 
Using the Specialization plane as seen in Figure 4 above allowed us to map the different iterations as they emerged from the data. It should be emphasised here that this mapping was not pre-planned. Rather, by aligning theoretically informed design considerations to the Specialization codes, we allowed the data to 'speak to us', thus providing for an opportunity to have a broader reflection on the project. Learning design led to code shifts, defined as a 'change in the legitimation code, such as from knowledge code to a knower code' (Maton, 2016a: 237). The iterative nature of the course allowed for reflection by both the participants and the facilitators, thus contributing to how we responded to each iteration. The degree to which the knowledge and knower attributes were strengthened is significant for us. We can see that in three of the four iterations our aims or course/workshop outcomes matched our participants' experiences (iteration 1, 2 and 4). However, the third iteration did not match participants' experiences. Its design requires strong theoretical knowledge $(E R+)$ but it was experienced as a relativist code by participants in that they could not engage with the specialist knowledge on their own (ER-), nor could they apply such knowledge to their own practice and development (SR-). Lamont and Maton (2008) refer to this as a 'code clash' between desired and actual outcomes. In our case, the learning design (asynchronous online, independent, little collaboration, voluntariness) was not appropriate for the 'dispositions' of the 'knowers' (Christie and Maton, 2011: 11). Building from this allowed us to use key concepts as a means to introduce the theoretical issues and making it easier for the participants to access the knowledge components of the module. This technique provides motivation for the participants and leads to stronger socialisation (Salmon, 2014).

\section{Discussion and Conclusions}

In this paper, we mapped the process of designing four iterations of an academic staff development intervention, which was aimed at supporting academics in curriculum design (in particular, Curriculum Officers). We set out to explore how certain design decisions impacted on participants' experiences and how data from participants' feedback, facilitators' observations, focus groups and facilitators reflections, impacted on the design of the various iterations of the intervention.

Adopting Kolb's experiential learning cycle, we built on the understanding that experiential learning foregrounds a "relational" engagement with knowledge, mirroring the complexity, messiness and uncertainties inherent in curriculum design processes, rather than a more traditional, 'technicist' and linear understanding of curriculum design based on measurable and predetermined outcomes and objectives (Tomkins and Ulus, 2016: 158). It was this desire to probe relational experiences that led us to recognise shifting codes. This allowed us to see the participants' experiences in terms of advantages and challenges. Gains, including building on the participants' (and facilitators') individual dispositions, risk taking, experimentation with new (and sometimes difficult models), critical readings and provocative thoughts, different points of entry and different 
levels of engagement, all point to the conclusion that navigating academic staff development in an online platform allowed for a similar relational experience between participants (as the knowers) and the content (the knowledge they sought to build) as in face to face workshops. However, how to build this relationship is different within face to face and online spaces and needs careful design and acceptance of limitations of each modality.

The four iterations have shown us how unfamiliar and new blended and online staff development was for both facilitators and participants and how difficult it was to reproduce the kind of learning engagement that happens seemingly easily in a face-to-face workshop, and how important it was, therefore, to create synchronous engagements in online teaching and learning, even if this meant limiting flexibility.

Specialization also allowed us to engage with the challenges of moving academic staff development online. Participants' experiences pointed to challenges in establishing routines, coping with change in culture or context, confronting transitions and new ways of being, interdisciplinary collaboration, and creating space for deep engagement. We see these challenges glaringly in iteration 3, which as described above could be seen as a 'code clash' - as the desired course design outcomes did not match participants' experiences. Chen and Maton (2011) describe a similar instance in their studies on Chinese students in Australia, who because of their previous school experiences and dispositions, could not engage in the more constructivist teaching offered, where focus was on the knower, and knowledge was implicitly embedded and direct instruction was limited, which led to a relativist-code learning experience for the students. Thus, we argue that context is so important in learning design.

If we believe that learning happens in liminal spaces, in the not-yet-known and not-yetexperienced, we need to think carefully about how to support staff into, across and out of these liminal zones, when preparing them for curriculum work - both face-to-face and online (Berger, 2004). Teräs (2016) suggests staff developers' need to be careful and work with/support the 'learning culture shock', the accustomisation process the learners/staff go through - which resembles the socialisation phases in a new cultural environment (Salmon, 2004). The above authors' argument reinforces the importance of careful learning design and continuous reflection and redesign, especially when creating online staff development experiences, which a year ago were still new to many academics.

Reflecting on the learning designs iterations analysed in this study, we heed Maton's (2016a) caution against enforcing false dichotomies in educational research. In our context, we do not place greater value on one code than another (i.e., we are not suggesting that a knowledge code is more valuable than a knower code or vice versa). Rather, we need to explore how theory allows one to engage with the deeper implications of context. In this case, the challenges encountered exposed us to the participants' varying notions of being (face to face and online) vis-a-vis their engagements with curriculum development, self, and others. That is, their process of becoming is twofold: 
becoming curriculum developers is both a knowledge-oriented discipline; and it is concerned with the knower. It is both about meeting quality criteria and understanding the complexities of designing curricula that speak to the realities of our learners and lecturers and allow them to flourish. Furthermore, curriculum design is not an individual task, and it is not a technicist engagement, but a collective sense-making and relational practice, that is in its very nature, complex, dynamic and transformative (Bester and Jones, 2019). While academic staff development is mostly concerned with the knower, our study showed that both knowledge and knower relations can be addressed, although it is not without tensions in curriculum development work because of the iterative, multilayered nature of the process and the differing conceptions of teaching and learning held by academic staff from different disciplines. Moving between messy but creative design conversations on the one hand, and prescribed, bureaucratic templates on the other, required complex translation work by participants, with intense support and scaffolding - which we were not able to successfully replicate in an online space as yet. This is not to say that it is not possible, but that each context needs to be carefully considered when designing courses, both face-to-face and online, and that design considerations (such as voluntariness) impact strongly on participants' engagement and consequently experiences.

Specialization in LCT allowed us to appreciate that the above challenges are not deficiencies per se, but rather the tools give us an opportunity to understand participants' experiences and make sense of our own design decisions. Using Kolb's experiential cycle, we were able and continue to reflect on how to strengthen both the knower and the knowledge in the context of academic staff development over time in iterative design cycles - which we will continue to engage with in future. Much has changed since 2019 and online academic staff development has become more familiar and common in these times of remote teaching and learning. However, the questions of how to offer academic staff development that can support both knowledge and knower remains largely unexplored.

\section{Author biographies}

Daniela Gachago is working at the Centre for Innovation in Learning and Teaching at the University of Cape Town. Her research focuses on supporting academic staff in the use of technologies to transform teaching and learning. She is also interested in innovative course and curriculum design drawing from co-creative approaches such as design thinking.

Barbara Jones has an adult education background and is an independent higher education researcher and curriculum development specialist. She is currently engaged in the Curriculum Transformation and Renewal project of the Academic Planning Unit, University of the Western Cape. 
Emmanuel Ekale Esambe lectures Academic Literacy at the Fundani Centre for Higher Education Development (Fundani CHED). He is currently the Coordinator of Student Feedback on Teaching and Courses at Fundani CHED, Cape Peninsula University of Technology. His research focuses on undergraduate students' academic development, specifically in literacy and educational technology.

Sonwabo Jongile is an Instructional Designer in the Centre for Innovative Educational Technologies (CIET) at the Cape Peninsula University of Technology (CPUT). He has more than 10 years of academic staff development experience, with focus on technology-enhanced teaching and learning pedagogical requirements and designing blended learning interventions in higher education.

Eunice Ndeto Ivala is an Associate Professor and Director of the Centre for Innovative Educational Technology at CPUT. Her research focus is on ICT-mediated teaching and learning in developing contexts. She holds a B.Ed Honoursdegree from the University of Nairobi; a MEd degree from the University of Natal, and a PhD in Culture, Communication and Media Studies from the University of KwaZulu Natal.

\section{References}

Bali, M. \& Caines, A. 2018. A call for promoting ownership, equity and agency in faculty development via connected learning. International Journal of Educational Technology in Higher Education, 15(46). https://doi.org/10.1186/s41239-018-0128-8

Baran, E., Correia, A.P. \& Thompson, A. 2011. Transforming online teaching practice: Critical analysis of the literature on the roles and competencies of online teachers. Distance Education, 32(3), 421-439.

Barnett, M. 2006. Vocational knowledge and vocational pedagogy. In Young, M. \& Gamble, J. (eds.) Knowledge, Curriculum and Qualification for South African Further Education. Cape Town: Human Sciences Research Council.

Barnett, R. 2009. Knowing and becoming in the higher education curriculum. Studies in Higher Education, 34(4): 429-440.

Barnett, R. 2012. Learning for an unknown future. Higher Education Research \& Development, 23(3): 247-260.

Beach, A., Sorcinelli, M.D., Austin, A. \& Rivard, J. 2016. Faculty Development in the Age of Evidence: Current Practices, Future Imperatives. Sterling, VA: Stylus Publishing.

Berger, J.G. 2004. Dancing on the threshold of meaning: Recognizing and understanding the growing edge. Journal of Transformative Education, 2(4), 336-351. doi: 10.1177/1541344604267697.

Bernstein, B. 2000. Pedagogy, Symbolic Control and Identity. Oxford: Rowan and Littlefield. 
Bester, M. \& Jones, B. 2019. Curriculum decision-making as a collective sense-making and relational practice. In HELTASA Conference 2019, Pedagogies in Context, p50. Makanda: Rhodes University.

Chen, R.T.-H. \& Maton, K. 2011. Absenting discipline: Constructivist approaches in online learning. Disciplinarity: Functional Linguistic and Sociological Perspectives. 129-150.

Christie, F. 2016. Secondary school English literary studies: Cultivating a knower code. In Maton, K., Hood, S. \& Shay, S. (eds.) Knowledge Building: Educational Studies in Legitimation Code Theory. London: Routledge, 158-174.

Clarence, S. 2014. Enabling cumulative knowledge-building through teaching: A Legitimation Code Theory analysis of pedagogic practice in law and political science. Unpublished PhD diss. Rhodes University, Grahamstown, South Africa.

Clarence, S. \& McKenna, S. 2017. Developing academic literacies through understanding the nature of disciplinary knowledge. London Review of Education, 15(1): 38-49.

Conana, C.H. 2016. Using semantic profiling to characterize pedagogical practices and student learning: A case study in two introductory physics courses. Unpublished PhD diss. University of the Western Cape, South Africa.

Cook-Sather, A., Matthews, K.E. \& Bell, A. 2019. Transforming curriculum development through cocreation with students. In Quinn, L. (ed.) Re-imaging curriculum: Spaces for disruption. Stellenbosch: SUN Press, 107-126.

Dall'Alba, G. \& Barnacle, R. 2007. An ontological turn for higher education. Studies in Higher Education, 32(6): 679-691.

Dewey, J. 1938. Experience and Education. New York: Touchstone, Simon \& Schuster

Engel-Hills, P., Winberg, C. \& Rip, A. 2019. Ethics 'upfront': Generating an organizational framework for a new University of Technology. Science and Engineering Ethics. https://doi.org/10.1007/s11948-019-00140-0.

Gachago, D., Pallitt, N. \& Bali, M. 2020. No size fits all: Design considerations for networked professional development in higher education. In Networked Learning Conference. https://doi.org/10.5040/9781474209496.0029

Gachago, D., Van Zyl, I. \& Waghid, F. Forthcoming. More than Delivery: Designing Blended Learning Spaces with and for Academic Staff. In Sosibo, L. \& Ivala, E. (eds.) Transforming Learning Spaces. Vernon Publishing

Goodyear, P.. 2015. "Teaching as Design." HERDSA Review of Higher Education Volume 2 2: 27-50. http://www.herdsa.org.au/wp-content/uploads/HERDSARHE2015v02p27.pdf (Accessed: 24 May 2020).

Heinze, A. \& Procter, C. 2004. Reflections on the use of blended learning. University of Salford, Manchester. [Online]. Available from: http://usir.salford.ac.uk/1658/1/42477445025H_CP__paper9_5.pdf (Accessed: 24 May 2020). 
Jones, B. M. \& Walters, S. 2015. Flexible learning and teaching: Looking beyond the binary of fulltime/part-time provision in South African higher education. Critical Studies in Teaching and Learning, 3(1): 61-84.

Kolb, D.A. 1984. Experiential learning: Experience as the source of learning and development (Vol. 1). Englewood Cliffs, NJ: Prentice-Hall.

Lamont, A. \& Maton, K. 2008. Choosing music: Exploratory studies into the low uptake of music GCSE. British Journal of Music Education, 25(3): 267-282

Lane, L.M. 2013. An open, online class to prepare faculty to teach online. Journal of Educators Online, 10(1).

Martin, J.L. 2016. Musicality and musicianship: Specialization in Jazz studies. In Maton, K., Hood, S. \& Shay, S. (eds.) Knowledge Building: Educational Studies in Legitimation Code Theory. London: Routledge, 193-213.

Leafstedt, J. \& Pacansky-Brock, M. 2016. A Step-by-Step Guide to 'Untethered' Faculty Development. EdSurge- Digital Learning in Higher Ed, (October). Available at: https://www.edsurge.com (Accessed: 24 May 2020).

Maton, K. 2007. Knowledge - knower structures in intellectual and educational fields. In Christie, F. \& Martin, J.R. (eds.) Language, Knowledge and Pedagogy: Functional Linguistics and Sociological Perspectives. London: Continuum, 87-108.

Maton, K. 2014. Knowledge and Knowers: Towards a Realist Sociology of Education. London: Routledge.

Maton, K. 2016a. Legitimation code theory: Building knowledge about knowledge-building. In: Maton, K., Hood, S. \& Shay, S. (eds.) Knowledge Building: Educational Studies in Legitimation Code Theory. London: Routledge, 1-24.

Maton, K. 2016b. Starting points: Reflections and architectural glossary. In Maton, K., Hood, S. \& Shay, S. (eds.) Knowledge Building: Educational Studies in Legitimation Code Theory. London: Routledge, 1-24.

Muller, J. 2007. On splitting hairs: Hierarchy, knowledge and the school curriculum. In Christie, F. \& Martin, J.R. (eds.) Language, Knowledge and Pedagogy: Functional Linguistics and Sociological Perspectives. London: Continuum, 65-86.

Networked Learning Editorial Collective (NLEC)., Gourlay, L., Rodríguez-Illera, J.L. et al. 2021. Networked Learning in 2021: A Community Definition. Postdigital Science Education, 3: 326 369.

Ngoasheng, A., Cupido, X., Oyekola, S., Gachago, D., Mpofu, A. \& Mbekela, Y. 2019. Advancing democratic values in higher education through open curriculum co-creation: Towards an epistemology of uncertainty. In Quinn, L. (ed.) Re-imaging curriculum: Spaces for disruption. Stellenbosch: SUN Press, 324-344. 
Ní Shé, C., Farrell, O., Brunton, J., Costello, E., Donlon, E., Trevaskis, S. \& Ecceles, S. 2019. Teaching online is different: Critical perspectives from the literature. Dublin City University. https://doi.org/10.5281/zenodo.3479402

Quacquarelli, N. 2020. Introduction. In: The Impact of the Coronavirus on Global Higher Education. Available: https://www.qs.com. (Accessed: 24 May 2020).

Rauth, I., Köppen, E., Jobst, B. \& Meinel, C., 2010, 'Design thinking: an educational model towards creative confidence', 1st International Conference on Design Creativity (ICDC 2010).

Republic of South Africa Department of Higher Education and Training (DHET) 2014.Policy for the Provision of Distance Education in South African Universities in the Context of an Integrated Post-school system. Pretoria

Republic of South Africa Department of Higher Education and Training (DHET) 2017. Open Learning Policy Framework for Post-school Education and Training, Second Draft for public comments Version 2.1. Pretoria.

Salmon, G.K. 2004. E-moderating: The Key to Teaching and Learning Online. London \& New York: Routledge Falmer.

Taheri, M., Unterholzer, T., Hölzle, K. \& Meinel, C. 2016. An educational perspective on design thinking learning outcomes. In The ISPIM Innovation Forum. Boston, USA: ISPIM.

Teräs, H. 2016. Design Principles of an Authentic Online Professional Development Program for Multicultural Faculty. Published dissertation. Tampere University: Tampere University Press.

Thomson, I. 2001. Heidegger on ontological education, or: how we become who we are. Inquiry, 44(3): $243-268$.

Tomkins, L. \& Ulus, E. 2016. "Oh, was that 'experiential learning'?!" Spaces, synergies and surprises with Kolb's learning cycle. Management Learning, 47(2): 158 - 178.

Quinn, L. \& Vorster, J. 2019. Why the focus on curriculum? Why now? The role of academic development. In: Quinn, L. (ed.) Re-imaging curriculum: Spaces for disruption. Stellenbosch: SUN Press, 1-22.

Vorster, J. \& Quinn, L. 2017. The "decolonial turn": What does it mean for academic staff development? Education as Change, 21(1): 31 - 49.

Vygotsky, L. 1978. Mind in society. The Development of Higher Psychological Processes. Cambridge: Harvard University Press.

Winter, J., Turner, R., Spowart, L., Muneer, R. \& Kneale, P. 2017. Evaluating academic development in the higher education sector: Academic developers' reflections on using a toolkit resource. Higher Education Research and Development, 36(7): 1503 - 1514. 